\title{
Environmental friendliness of educational innovations and agency of consumption of educational services
}

\author{
Olga Posypanova ${ }^{1}$, Petr Menshikov ${ }^{1}$, Anastasia Demchuk $^{2}$, Albina Sibagatullina ${ }^{2}$, \\ Ekaterina Kraynova ${ }^{3}$, Aleksandr Kosov ${ }^{1,4}$, and Mariam Arpentieva, ${ }^{2, *}$ \\ ${ }^{1}$ K.E. Tsiolkovskiy Kaluga state university, 248023, Kaluga, Russia \\ ${ }^{2}$ Surgut state university, 628412, Surgut, Khanty-Mansi Autonomous Area - Yugra, Russia \\ ${ }^{3}$ M.M. Speranskiy Law Institute, A.G. and N.G. Stoletovs Vladimir State University, 600000, \\ Vladimir, Russia \\ ${ }^{4}$ Kaluga Complex Center for Social Protection "Care", 248000, Kaluga, Russia
}

\begin{abstract}
The environmental imperative is one of the leading imperatives of our time. Its understanding varies widely in different contexts. One such object is educational innovation. The theoretical basis of variations is two main groups of ideas: 1) the idea of development as a process and a result of gradual, "stable", often "planned" / projected quantitative "accumulations", and 2) the idea of development as a crisis, coupled with periods of abrupt / revolutionary, "emergent integrative and qualitative transformations, the exit of the system from the state of homeostasis to a new state, transparent for its members. The purpose of the study is to analyze the problems of environmental friendliness of educational innovations in the context of ensuring the subjectivity of the consumption of educational services. The research method is a phenomenological theoretical analysis of the problems of educational innovations within the framework of traditional and modern concepts of the development of society. The concept of the development of society, reflecting the general ideas about its functioning and improvement, as well as the formation and development of its members, acts as the basis for education reforms. Each of the concepts provides its own view of the forms and goals of education as a process of formation and improvement of subjectivity.
\end{abstract}

\section{Introduction}

The environmental imperative is one of the leading imperatives of our time. Its understanding varies widely in different contexts, including within the framework of concepts describing the development of natural and cultural sites. One such object is educational innovation. The theoretical basis of variations is two main groups of ideas: 1) the idea of development as a process and a result of gradual, "stable", often "planned" / projected quantitative "accumulations" against the background of states of adaptation, "harmony" and homeostasis, and 2) the idea of development as a crisis, coupled with

* Corresponding author: mariam_rav@mail.ru 
periods of abrupt / revolutionary, "emergent" (unpredictable), integrative qualitative transformations, the exit of the system from the old state of homeostasis to a new, more perfect and "authentic", transparent for its members and the system itself. The dialectical approach, systemic methodology unites these concepts as stages of development, however, in reality, there are tendencies for their separation as desirable and undesirable options for improvement. Moreover, in modern times and in the history of mankind, there have been and exist whole periods when development as a value is completely denied and / or replaced by one of its types, as now - in the popular concept of "sustainable education". With all the popularity of the doctrines of "breakthrough and disruptive innovations", startups, innovations and renovations, etc., the models of "sustainability / stability", security / anti-crisis, foresights as projects (controlled scenarios) of the future, support of certain "new world orders", while innovations themselves, start-ups, "disruptive technologies" and other innovations turn out to be a means of avoiding significant changes. The leading problems of environmental analysis in the field of education and culture are:

1) measures and forms of management or intervention or non-interference of the state and business in education. Certain forms and measures of intervention, for example, in the model of modern pragmatists who impose on education the requirements of strict compliance with the requirements of "sustainable" business, as well as violating human rights and obligations and the very humanity of "security", are anti-ecological. The environmental imperative speaks of the importance of a dialogue between all stakeholders in education, including within the framework of the model of education as an institution through which the older generations take care of the younger, as an institution for the reproduction and development of society, including in its periods of crisis,

2) the formation and transformation of the "educational culture" of society and the goals of education. The transformation of the educational culture of society within the framework of the concept of training a comprehensively developed person - a person, a partner and a professional is in greater "ecological" conformity, an authentic understanding of education as an institution of cultural transmission, and the understanding of education as the sale and consumption of educational services is associated with a much less authentic concept of education as business. The focus of education on the improvement and development of society and man is ecologically more correct than the focus on their "sustainable" functioning,

3) training and retraining of teachers and educational programs and program complexes, including in the context of changing (innovative and other) concepts of education and in the context of those theoretical and methodological "accumulations" that education itself has made (achieved). It should be noted the importance of the "ecological" compliance of teachers and programs with the ideas about education specified in the previous paragraph and the state and achievements of science, art, social relations and production that humanity has reached and will achieve (forecasts and foresights) in the coming decades, which constitute the prospect of labour training and professional life of one generation. The opposite pole is represented by education that prepares a "one-button specialist", roboticresistant and competitive for a certain period of his life and is forced to constantly and "continuously", "throughout his life" to acquire educational documents in order to survive in the world of digitalization, precarization, standardization and other deformations of labour and other spheres of social relations,

4) the environmental friendliness of the subject content, technologies and methods of education - their correspondence to each other, the level of education, the modern level of development of science, art, society and production, etc. ,

5) the focus is on the problems of the subjectivity of education: the "complete" subjectivity (agency) of development (its harmony and authenticity) and the deformed, incomplete subjectivity [1] of the consumption of educational services. 


\section{Research methodology}

The purpose of the study is to analyze the problems of environmental friendliness of educational innovations in the context of ensuring the subjectivity of the consumption of educational services. The research method is a phenomenological theoretical analysis of the problems of educational innovations within the framework of traditional and modern concepts of the development of society. The concept of the development of society, reflecting the general ideas about its functioning and improvement, as well as the formation and development of its members, acts as the basis for education reforms. Each of the concepts provides its own view of the forms and goals of education as a process of formation and improvement of subjectivity.

\section{Research results}

One of the signs of innovations is their subjective nature: subjects create and implement innovations. Otherwise, we are talking about pseudonovations and pseudopersonality, as is typical for the concept of "educational services", producers and consumers of these services. Research into the psychology of the subject (N.V. Bogdanovich, A.V. Brushlinskiy, V.V. Znakov, Z.I. Ryabikina, E.A. Sergienko) and subjectivity / agency as an individual education (N.M. Borytko, E.N. Volkova, E.I. Kazakova, F.G. Mukhametzyanova, A.K. Osnitsky, V.A. Petrovskiy, V.I. Slobodchikov) are still not too numerous, but very relevant and significant. Subjectivity / agency is a characteristic of achievements in human development, subjective properties appear only at a specific stage and with a specific type of (intact) development. It is associated with the balance and activity of the processes of exteriorization and interiorization, external and internal formation, awareness and implementation.

Comprehension of subjectivity / agency in ontogenesis shows that human development is associated with the growth of subjectivity and overcoming "objectivity", ie. total dependence of an individual on external conditions. At the same time, subjectivity is manifested in everything, including the attitude towards people. Subjectivity or agency is the stage of an individual's activity, at which he achieves the integrity / integrative of all types of his / her activity and autonomy as freedom (co)creativity and independence. Subjectivity is reflected in the system of relations to the world and oneself, the realized strategy of life as a reflection of an individual's readiness and ability to make interdependent transformations in the external and internal world. The subject of life (and education) is inseparable from the world (education), is included in it, but at the same time consciously opposes treating oneself (consuming oneself) as a soulless thing, an object of manipulation, and also opposes treating oneself only as a consumer of things and services, not part of a single being. Subjectivity / agency in an individual is inextricably linked with the productivity and efficiency of his / her activities, the activity of the subject has a transformative, creative character. In addition, agency is the realization of the ability and readiness not only to appropriate (interiorize), translate, but also to generate the meanings of activity as actual values. Education is a universal form of the formation and development of subjective reality in the time of history and in the space of culture [2, p. 5]. Education is the possibility and reality of the subjective development of an individual as a person, a partner and a professional. The modern education system, its institution - time and space, in which conditions are created for the survival and development of an individual in a modern complex, crisis of the world (it directed by the forces of global governance to collapse and degradation called "sustainable development" and "new world order"). To prepare an individual for life in it, to learn to live fruitfully and effectively in conditions of uncertainty - this is the mission of university, secondary, and even preschool and primary education [3]. 
Education is the formation and development of an individual as a person, a partner and a professional (an integral, complex, improving unique subject of (co)creative activity) [4, 5].

From the socio-psychological point of view, agency is the ability to engage in relationships with other (significant) people, to contribute to their development and the development of social situations, becomes an agent of changes in their life and the life of the "outside" world as a whole [6]. The subject, as a carrier of educational and professional activity, is directly included with the help of this activity in the transformation / comprehension of the reality surrounding him. To become a subject of educational and professional activity means to master this activity, that is, to become capable and ready for its implementation and creative transformation, to form one's attitude towards it and, through this attitude, towards other people and social situations [7]. Subjectivity / agency is inextricably linked with the degree of an individual's identification with the world of culture, which forms those "internal conditions through which only external causes, influences, etc. always act" [8]. Agency also acts as intersubjectivity, co-existence of people in the world, the ability and desire to build meaningful (referential) relationships with other people [6]. Self-determination as self-regulation is a condition on the way of coordinating one's and partners' abilities and readiness to solve specific educational, professional and other tasks. It also means the orientation of partners to their own and others' subjective experience, respect for freedom and recognition of the responsibility of each and every one for their individual or joint life choices, processes and results of cooperation and other forms of activity. Subjectivity is the need to be present in the life and activities of other people, to be included through "personal contributions" to the lives of other people, through active participation in joint activities [7]. At the same time, subjectivity (as "agency") is a person's ability to be autonomous, independent, independent of other people, their opinions, norms, including distance from the influence of the external environment, as well as offering this environment their opinions, norms, influence on them [9]. Subjectivity can also be viewed as a way of human being aimed at transforming oneself, others, social situations and the world as a whole, a leading property of human subjectivity [10]. Therefore, H. R. Markus and S. Kitayama even describe a conjoint agency - the desire of people to interact, to act as a group [11]. The development of subjectivity is associated with the extent to which the conditions surrounding a person, including the conditions of education, and to what extent his internal "conditions" (motives of development, values and goals, experience, etc.) contribute to the awareness of oneself as a member of the community, as a bearer of socially significant ideas and norms [12]: the choice of a teaching and learning strategy, in particular, actively or reproductive, "deep" or "superficial", is associated with the level of formation of the idea of oneself as a subject (actor) and a member of the community [9, 13]. Subjectivity is also the ability and readiness to distinguish oneself as an actor and co-actor from the process and results of educational and pedagogical activity, the ability and readiness to recognize oneself and another as a subject, a person, partner and professional.

R.I. Anisimov notes that at present, subjectivity in its full and complete form is usually not revealed by a person either in life in general, or in education in particular. Different individuals and social groups usually develop only certain aspects of subjectivity [1]. Considering the problem of incomplete subjectivity, he notes the existence of two extremes, namely, as the concept of an "inactive individual" in the context of the concepts of "understanding sociology" (symbolic interactionism, phenomenological sociology, etc.) about the formation and development of identity outside the analysis of the social conditions of this formation, and as the concept of the "unconscious agent" in the "naturalist" paradigm, which emphasizes the social conditioning of behavior and is incapable of serious comprehension of the consciousness and identity of the individual. Subjectivity is the structure of consciousness and activity of the individual as an actor 
(doer), which results in a (co)creative transformation of the world. In turn, the structure of consciousness and activity includes those introduced from the outside (internalized) by society (values, roles, behavioral patterns) and internally, by comprehending and realizing oneself as different from others. Activity is an active transformation of the world or a rejection of such a transformation (passive adaptation to it or lack of adaptation). Proceeding from an active position in relation to themselves and to the world, they are transformed, proceeding from a passive position are they adapt to them (or refuse to adapt, completely abandoning activity as such). In the modern world, there is a consistent development, strengthening of "I" -identity against the background of weakening of "We" identity: the phenomenon of self-control / conscience is replaced by a more "external" fear of punishment and shame, and, in the extreme, can be replaced by the fear of punishment in the process of repentance. According to the model of J. Mead, in the course of socialization, an "internalized Other" or "We"-identity is first formed, on its basis further emerges "I" -identity as an opportunity to observe oneself from the outside and act based on the expectations of other individuals. In this case, subjectivity / agency is achieved due to the simultaneous development and existence of "We" -identity, "I" -identity and activity. Thanks to agency, an individual turns into a creative person who remakes reality, and thanks to "We"-identity, a person acquires the experience of past generations, which is the starting point for the creativity of the individual. Thanks to "I" -identity, or self-awareness, an individual can critically assess the experience of his predecessors and, starting from it, create something new [1]. The loss of subjectivity usually manifests itself in the fact that a person demonstrates inappropriate behavior: he / she shows meaningless, ineffectual activity, fussiness, simulation of activity, or, conversely, is unreasonably inactive.

In the typologies of incomplete and deformed subjectivity, R.I. Anisimov, T.A. Olkhova and other researchers, these three features are not equivalent. There are two types of external conditions, or situations $[1,4,5]$. The first type is repetitive, routine or everyday situations. The second type is situations that are not repetitive, not routine or not everyday: the moment of birth and the moment of death do not depend on the individual, therefore they cannot always be attributed to "social action" (in the terminology of M. Weber). So, according to R.I. Animisov, the most typical types of incompleteness of agency include [1] 1) closure (development of "I"-identity, without the development of "We"-identity and activity), while a person can only destroy himself or freeze in the immutability (eternity, timelessness) of his "I" ", 2) fantasizing (the development of "I" and "We"-identities without the development of activity), gives rise to people with a split, "unhappy" consciousness, in which "you have to" ("We"-identity) and "I want" ( "I"-identity), their influence on the transformation of the world indirectly by other people who implement their projects or involves self-sacrifice, 3) nonconformism (development of "I"-identity and activity without the development of "We" -identity), in which personal interests and selfinterest are at the head of everything, activity is manifested in the destruction of "We"identity, which appears under the name of the old, 4) conformism (the development of "We"-identity without the development of "I"-identity and activity) is associated with submission, the desire to destroy and sinfulness of the "I"-identity, adaptability and the absence of one's own opinion, the absence of anxiety about the incoherence of one's judgments - ease of manipulation. Uncreative and inactive, one-dimensional people addressees and victims of marketing campaigns, electoral technologies, collectivists who love routine work and copying from templates, 5) totalization (the development of "We"identity and activity without the development of "I"-identity), the active imposition of external social attitudes not only in relation to oneself, but also to others among such "ideal citizens" is associated with the improvement of the known, suffer from changes, up to suicide, due to the loss of status, job, place, time, etc., there is no uniqueness, uniqueness, the finiteness of his "I", 6) simulation and hypertrophy of activity (development of activity 
without the development of "We"-identity and "I"-identity). People play life for the sake of the game itself, therefore they can risk for the sake of a sense of life. A group of individuals with different types of incomplete subjectivity, uniting into one whole, can achieve the status of a collective subject living according to their own laws. The problems of the formation, implementation and development of subjectivity in the modern world are often associated with the formation, functioning and disintegration of the "consumer society" and its foundation, the postmodern culture [14]. It is a society of total simulations and imitations [15], including simulations of technology and education, man and culture, development and life as such. This is the place and time when it is vitally important for a person striving to preserve himself as a subject to understand what a person is and what are not [16]. The simulation has reached the stage at which social relations themselves are imitated, culture is imitated, man / woman and his / her subjectivity are imitated. Thus, scientists and pedagogical practitioners of our time note that sociality is becoming more and more "easy", functional-pragmatic: connections between people are established and maintained on the basis of ideas about their functionality [17].

According to classical psychoanalysis, these are fictitious connections formed on the basis of fictitious life goals. Such connections, "easy sociality" in general, include: lack of human attachment and responsibility, obligations and rights, dignity and respect, reduction of social ties to biological and economic, strictly limited "corridor" of tolerance and renormalization of life (traditional values) [17]. The boundaries of intolerance are marked by traditional, "difficult" sociality, with its striving for truth, humanity, culture, striving to "load" a person with values and goals, experience and understanding, choices and obligations, - to subjectivity. There is a progressive fragmentation of society: its division into ("new") tribes, granulation of society "according to interests." This fragmentation forms a non-structured (at the level of ideas and doctrines) a controlled human anthill [18], or, more precisely, a human-termite mound. Consumption, including consumption of oneself, becomes more and more obligatory and significant for those who are still striving to form a more or less stable identity [19, 20]. The search for meaning [21, 22] is replaced by imitations of search and choice: only a "naked" / socially or physically dead person cannot and does not strive to have, only he can not have. But a person living in society is forced to have and is forced to consume, including education, life as a whole. He does this at least in order to be able to survive in a society where any protests are successfully assimilated and become objects and forms of consumption. The need for work, the need for education, for friendship and love are replaced and replaced by the desires of the consumption of labor, education, friendship, love, also the consumption of life itself, the purchase of time and space of life, life resources, etc. In this case, the "one-dimensional" understanding of oneself and the world, the same "one-dimensional", simplified behavior and values, mean the loss of aspiration and ability to reflect as "critical thinking", and, most importantly, to subjectivity and opposition. An individual agrees to be a consumer of educational services, one way or another assuming that his role is reduced to passive procedures for purchasing documents on education, but not acquiring professionally, personally and interpersonal important competencies (systems of knowledge and skills). Here we are already talking not so much about violations of the ecology of education, but, according to apt metaphors of foreign researchers, the death of the university, school, and education in general. The division of the school into mass and elite, as well as the mechanism of "continuous" education with its multiple additional and alternative forms of advanced training, retraining, etc., serves the progressive destruction of education, primarily mass education, and, as a consequence, the destruction of a $\mathrm{n}$ individual and culture. It is no coincidence that scientists write about "constitutional stupidity", "patchwork consciousness" and other signs of degeneration in modern human. 
"Structureless" control (in which consumption determines who we, as individuals, are, and what, as a society, we want to be [23]), does not imply any need for subjectivity, subjectivity is opposite to it. From an ecological point of view, humans and insects are too different species to be governed in the same way, however, international structures, usually associated with transnational corporations, seek to govern in this way. Their way of managing humanity, thus, is designed to destroy humanity and culture: large-scale, efficiently. On the way to such destruction, in order to ensure personal and general security, there is a need for strict structural management ("vertical of power"). At the level of the individual, morally, socially, psychologically and physically consuming himself / herself and other people, a person leads himself and society to (self)destruction, to fascism and cannibalism. An individual finally deprives himself / herself of the opportunity to choose: "naked life" is constituted as controlled from the outside [24, 25], and documents on the purchase of educational services do not have any power to turn naked, objective life into the life of an individual as a subject. To help society get out of this state, one can use technologies of intersubjective management: reflected by the models of evergetics by $\mathrm{V}$. Wittich, direct or deep democracies by A. Mindell, and "second democracy" by A. Adler. Acting as subjects, actors, people, in including with the help of polyagent artificial intelligence technologies, currently aimed in the opposite direction (the final separation of control functions from a person) can restore, realize the state and quality of subjectivity / intersubjectivity. Modern cybernetics of the third-fourth levels comprehends precisely these processes: polysubject (and additional polyagent) procedures for managing communities. Another option for restoring subjectivity, resubjectivization, may be the "great refusal" as a real opposition to all-pervading control, desubjectivization.

The future of learning correlates with the radical transformation of pedagogical models, content and methods of betrothal and upbringing, with the transformation of the processes and results of learning (kind of learning) and learning (kind of teaching) [26]. At the same time, the issues of human becoming a subject (personality, partner and professional) in the context of these changes are practically considered mainly declaratively. There are many studies stating the importance and inevitability of change, noting the direction of change - it is also enough, but studies that concretize the sources, "types" and consequences of changes at the level of personality, interpersonal relations and educational and professional activities are frankly few. An example of the amazing "emptiness" of practical programs for such transitions can serve as any educational standard and any curriculum developed on its basis today, indicating the formation of "competencies" of the spiritual / moral type. Without touching upon the issues of inattention to the quality of the methodological, psychological, spiritual ensuring education in general, we note the nature of the presentation of requirements for the development of programs and other educational and methodological developments, allegedly intended for the formation and development of spiritual / moral competencies, bordering on farce. Such programs provoke the desacralization of education and culture, scholasticism and pseudoprofessionalism / deprofessionalization, lead to states of "social infantilism", the loss of subjective manifestations. The general emasculation of the strongly (as standards) recommended for the formation and development of lists of subject competences and other requirements for the design of programs, etc., also contributes to this process. Even within the framework of research on "inclusive" education, subject, educational and professional competences are opposed (!) to the knowledge and skills of people in the field of compatibility, readiness and ability to cooperate and help each other. Against this background, subject teachers seem unnecessary, and competencies are massively available: it remains to wait, competencies can be "built" into any induvidual through various biological and digital technologies (such as "chipping"), when teachers are replaced by "artificial intelligence" or its technological counterparts. 
The "spiral of silence" associated with this and other problems is twisting even now: concentration camp technologies are being introduced using the "discourse of care" traditional for the consumer society. This discourse provides the fullest possible public access to control over which care is declared (feigned), and to whom these means of "care" are successfully sold [14]. Fraud (an important weapon of which is the substitution of concepts) has become not only common in modern "civilized" societies: it is widely used at various levels and in various situations of management and other "care" about people, starting with the level of international, transnational corporations, etc. . The discourse of "caring" is well traced in the descriptions of modern education [26, 27, 28]: the concepts of comfort, convenience, ease, etc. become central here. In education, the discourse of care is part of the discourse of the consumption of educational services: all that a person needs to get an education (documents about him) is to pay. The understanding of the fact that any work, including educational, is somehow difficult is fading into the shadows: it does not exist outside the efforts, by practicing which an individual achieves a state of control over himself / herself and, in part, the world around him / her. Remuneration for educational work - subjectivity, humanity, culture, development of society and individual, and not the economic benefit of transnational corporations.

However, in reality we see something different: modern education is strictly controlled by innovation and pseudo-innovation in such a way that its goals become directly opposite to both the goals of education and the goals of life. They are pathocratic [29, 30]. Scenarios of pathocratic relations [31] in society and education are described in detail in the works of researchers of pragmatically oriented education, upbringing and training of a person who is more or less able to compete with other people and with artificial intelligence ("roboticproof") The idea of the fullness (integrity) of being, subjectivity, development as superiority an individual ("one button") above themselves and artificial intelligence in this context is not considered at all [32].

In studies of sociopathy and pathocracy [31], in studies of the digitalization of education and human "mechanization" by G. K. Zhukova, V. V. Spasennikov and many other critics $[33,34]$, it is noted that sociopaths sometimes form highly organized groups [31], called the mafia in classical Soviet psychology. The general secret of success for a psychopath of any type and pathocracy in general is the desire and ability to make his / her victim believe that the danger to him / her does not come from him / her , but from other people or circumstances. Sociopathy / psychopathy is usually hidden under the guise of normality and under masks of caring, protection from danger, etc. This, as already noted, is the traditional discourse of "care" for the culture of consumption, which provides unlimited opportunities for profit - leading for the capitalist model of value relations [14], understandable even for robots [32], the basic value of whose work is "encouragement", benefit. To live realizing this value, it is obvious that subjectivity is not needed. These individuals do not advertise their destructive or openly criminal behavior. Scientists of different directions and schools have repeatedly called them predators, cannibals, etc. For them, a person, including a student, is of no value. Most often, it acts as a threat if it recognizes the predatory nature of a sociopath or "products" created by him or by his order (including in the form of artificial intelligence and other digital programs, devices, technologies). An individual is also rejected if they are more "competitive" than a sociopath. Even in the context of digital education, already at the stage of developing it as a system, it is often not so much about strengthening the individual himself / herself, not about "organ projection", but about replacing or imitating an individual, competing with a person and / or controlling a person. Therefore, a number of ethical problems and risks arise. The very idea of superiority over others as the central idea of life for an individual, starting with A. Adler, is considered as pathologizing: it does not even help to survive. It is obvious that this type of human existence is formed by the entire culture of consumption and is consolidated by the current 
model of education as the sale and consumption of educational services. However, survival, including in the most severe conditions, is based on relationships of love, mutual assistance (in relationships with specific people), and, if nothing else remains, on those spiritual meanings that structure the existence of a specific person [35]. Therefore, education, built as a sale of services, cannot give a human much: the "care" of the older generations for the younger generations is only imitated in it. This is an anti-ecological education.

Therefore, nowadays teachers of our time and education in general have a choice. Modern educators may also strive to implement the "democratic" ideas of "My Creed" or even "Mein Kampf" of the century before last and last, created by J. Dewey and his predecessors and associates, adopted by Nazism in the mid-20th century [36, 37, 38]. They can overlay these outdated and inhuman relationship templates with the realities of the present century [32]. Or they can look to the present and the future without forcing a person to be who they are not. They can talk about the importance of pedagogy of emotions, about developmental pedagogy: such pedagogy is addressed to the harmonious, comprehensive, full-fledged development of a person, upbringing in him / her and bodily culture, and psychological culture (including emotional intelligence), and spiritual culture (morality and the experience of coping with difficulties) [39, 40, 41]. B.E. Fishman notes that organizational, systemic adjustment of processes in the educational system of a university can become effective if it focuses not only on updating the requirements for universities on the part of the state and society. It is equally important to focus on the factors that determine the formation of the subjectivity of modern students in the educational activities of the university [38]. The main problem now is productive and effective innovations that will help return education to its original values and goals, update and enrich the content and methodology, making it more environmentally friendly in relation to the development of children, adolescents, youths and adults $[42,42]$.

\section{Conclusion}

Analysis of the environmental problems of the development of education in the context of factors and conditions that promote and hinder the development of education and a person as a subject, including innovations in education and the environmental friendliness of these innovations, made it possible to identify a number of problems:

1) the problems of transformations and deformation of a person's self-understanding of himself and the world as human, including the problems of rejection of subjectivity / activity, creativity, responsibility and love,

2) problems of deformation of relations, their pathologization, alienation, normalization of models aimed at rejection of the human and the reification of man, simulation of relationships,

3) the problems of deformation of educational and professional relations, reducing the requirements for training a person with a "comprehensively developed", fully functioning, "organismic" integrity (A. Maslow, C. Rogers), striving to realize and actualize himself / herself, his / her mission (talents and intentions ), to a "robotic-resistant" (J. Dewey, J. Aoun) specialist of "one button", ready to act as a competent consumer and a consumed executor of orders and rules set by those who are behind artificial intelligence.

The environmental imperative in modern education and in the creation, implementation and evaluation of the results of innovations in education is one of the most important, albeit difficult to understand and implement. Variants of its interpretation include the traditional concepts of development as a unity of stable and crisis periods of qualitative and quantitative changes, and modern versions of the concepts of "sustainable development", masking the stagnation and involution of natural and cultural objects. The theoretical basis for variation is: 
1) the concept of "sustainable development" as a process and result of gradual, "sustainable", often "planned" / projected functional cycles of reproduction of society and its structures and relatively small, including supposedly environmentally friendly, safe quantitative "target" increases (population, culture, education) and losses, as well as other "savings" and spending, against the background and in order to maintain "problem-free", comfortable, states (adaptation, "harmony" and homeostasis, guaranteeing unlimited consumption of a limited number of "competent", "held" as people chosen and served by digital devices and "inferior" to them in development and capabilities of people of a "lower" social, psychological, physiological status),

2) the concept of the development of education as a crisis, coupled with periods of abrupt / revolutionary, "emergent" (sometimes unpredictable), integrative qualitative transformations, in the exit of the system from the old state of homeostasis to a new, more perfect and "authentic", transparent for its members and the very system, the environmental friendliness of the functioning and improvement of which is achieved by the fact that there are no or minimized attempts of directive, violent influence on the system, its control in order to suppress "undesirable," dangerous "for society and a person changes that go beyond the" planned ", projected, "target" states (foresight).

The development of education, culture and society as a whole as a value is completely denied and / or replaced by one of its types, and innovations and other innovations turn out to be a means of avoiding significant changes, including changes and transformations in the distribution of wealth / wealth, rights / power.

The leading tasks of environmental innovations in the field of education and culture are:

1) The environmental imperative affirms the need for a dialogue between all stakeholders and subjects of education, including within the framework of the model of education as an institution, through which the older generations take care of the younger ones, as an institution for the reproduction and development of society, including in its periods of crisis. Dialogue means maintaining the position of authoritarian government and business interference in education.

2) The focus of education on the improvement and development of society and man is ecologically more correct than the focus on their "sustainable" functioning. It is necessary to form and transform the "educational culture" of society and the goals of education. The transformation of the educational culture of society within the framework of the concept of training a comprehensively developed person - a person, a partner and a professional is in greater "ecological" conformity, an authentic understanding of education as an institution of cultural transmission.

3) It is necessary to observe the environmental friendliness of the subject content, technologies and methods of education - their correspondence to each other, the level of education, the modern level of development of science, art, society and production, etc.

4) It is necessary to "ecological" compliance of teachers and programs with the concept of the essence of education as an institution of culture, compliance of education with the state and achievements of science, art, social relations and production that mankind has reached and will achieve (forecasts and foresights) in the coming decades, which constitute the future training and professional life of one generation.

5) The most important environmental requirement is the requirement of the subjectivity of education: the "complete" subjectivity (agency) of development (its harmony and authenticity).

\section{References}

1. R.I. Anisimov, RGGU Bulletin. Seria Philosophy. Sociology. Art criticism 13(56), 294-305 (2010) 
2. V.I. Slobodchikov, Development of subjective reality in ontogenesis. Abstract of Grand PhD dissertation (IPI RAO Publ., Moscow, 1994)

3. R. Barnett, Understanding the University. Education in modern culture (Propilei, Minsk, 2001)

4. T.A. Olkhovaya, Formation of the subjectivity of a university student (OSU Publ., Orenburg, 2006)

5. T.A. Olkhovaya, O.V. Prikhodko, The university complex as a regional center of education, science and culture: materials of the All-Russian scientific and methodological conference (Orenburg State University, Orenburg, 2020)

6. V.A. Petrovskiy, M.V. Borodenko, Psychological newspaper 1 (2019) https://psy.su/feed/7827/

7. S.S. Kashlev, S.N. Glazachev, N.I. Sokolova, Bulletin of the International Academy of Sciences (Russian section), 20-25 (2011)

8. A.V. Brushlinskiy, Psychological journal 12(6), 3-10 (1991)

9. L.A. Stakhneva, Uchenye zapiski Oryol State University. Series: Humanities and Social Sciences 6, 464-470 (2011)

10. V.I. Slobodchikov, E.I. Isaev, Fundamentals of psychological anthropology. Human Psychology: An Introduction to the Psychology of Subjectivity (Shkola-Press, Moscow, 1995)

11. H.R. Markus, S. Kitayama, Nebraska symposium on motivation 49, 1-58 (2003)

12. E.Yu. Korzhova, F.G. Mukhametzyanova, R.R. Khairutdinov et al., Kazan Bulletin of Young Scientists 1.3(3), 17-22 (2017)

13. E.N. Volkova, Subjectivity as an integrative property of the teacher's personality: Dis. cand. psychology (Psychol. Institute of RAO, Moscow, 1992)

14. J. Baudrillard, Consumer Society. Its myths and structure (Republic Publ., Cultural Revolution Publ., Moscow, 2006)

15. J. Baudrillard, Simulacra and simulation (Tula Publ., Tula, 2013)

16. B.A. Didenko, M.V. Boykov, What is man? The main question (Consciousness Publ., Moscow, 2010)

17. A. Amin, N. Thrift, Cities: reimagining the urban (Polity Press, Cambridge, 2002)

18. A.A. Zinoviev, Global human anthill (Tsentrpoligraf Publ., Moscow, 2000)

19. D.R. Rakhmankulova, Thing as a measure of human culture. Abstract... diss. PhD in philosophy (NSPU Publ., Nijniy Novgorod, 2005)

20. D.K. Tihaze, A.S. Kurilova, Journal of Sociology and Social Anthropology XIV 5(58), 121-128 (2011)

21. V. Frankl, Man in search of meaning (Progress Publ., Moscow, 1990)

22. B. Smart, Consumer Society (SAGE Publications, New York, 2010)

23. S. Zukin, The Point of Purchase (Routledge, New York \& London, 2005)

24. J. Agamben, Blue sofa 10-11, 29-46 (2007)

25. H. Marcuse, One-Dimensional Man: Studies in the Ideology of Advanced Industrial Society (Routledge, New York, London, 2013)

26. C.L. Scott, The Future of Learning 1-3 (UNESCO Education Research and Foresight, Paris, 2015)

27. G.K. Kassymova, M.G. Yurkova, T.A. Zhdanko et al., Bulletin of National Academy of Sciences of the Republic of Kazakhstan 6(382), 195-200 (2019) 
28. G.K. Kassymova, G.A. Stepanova, O.P. Stepanova et al., International Journal of Education and Information 12, 171-176 (2018)

29. A. Gurumurthy, Ch. Nandini, The Wicked Problem of AI Governance, Artificial Intelligence in India (Friedrich-Ebert-Stiftung India Office, New Delhi, India, 2019) http://library.fes.de/pdf-files/bueros/indien/15763.pdf

30. A. Gurumurthy, N. Chami, Development 1 (2021) https://doi.org/10.1057/s41301021-00287-z

31. A.M. Łobaczewski, Political Ponerology: A Science on the Nature of Evil Adjusted for Political Purposes (Les Editions Pilule Rouge, France, Castelsarrasin, 2017)

32. J.E. Aoun, Robot-Proof: Higher Education in the Age of Artificial Intelligence (MIT Press, New York, London, 2017)

33. M.R. Arpentieva, Foresight Education: Values, Models and Technologies of Didactic Communication of the XXI Century (Altaspera Publishing \& Literary Agency Inc., Canada, Toronto, 2018)

34. S. Mitri, D. Floreano, L. Keller, PNAS 106(37), 15786-15790 (2009) doi:10.1073/pnas.0903152106

35. B. Smart, Consumer Society (SAGE Publications, London, 2010)

36. E.P. Cubberly, Public School Administration (Nabu Press, New York, 2014)

37. J. Dewey, My Pedagogical Cree (Forgotten Books, New York, 2017)

38. B.E. Fishman, Higher education in Russia 28(5), 145-154 (2019) https://doi.org/10.31992/0869-3617-2019-28-5-145-154

39. M.R. Arpentieva, I.V. Gorelova, K.G. Kassymova et al., Bulletin of the National Academy of Sciences of the Republic of Kazakhstan 1(383), 242-254 (2020)

40. S.V. Lavrinenko, I.V. Gorelova, G.K. Kassymova et al., Bulletin of the National Academy of Sciences of the Republic of Kazakhstan 1(383), 264-276 (2020)

41. M.R. Arpentieva, G.K. Kasymova, S.V. Lavrinenko et al., Bulletin of the National Academy of Sciences of the Republic of Kazakhstan 3(379), 158-168 (2019)

42. D. Nugent, A. Suhail, Urban Inequalities. Palgrave Studies in Urban Anthropology (Palgrave Macmillan, Cham, 2021) https://doi.org/10.1007/978-3-030-51724-3_8

43. El. Pauwels, The Geopolitics of Converging Risks: The UN and Prevention in the Era of AI (United Nations University Centre for Policy Research, 2019) 